\title{
Erratum to: 1-Year outcome of concomitant intracarpal lesions in patients with dislocated distal radial fractures: a systematic assessment of 78 distal radial fractures
}

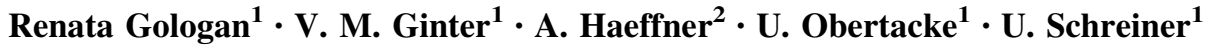

Published online: 17 February 2016

(c) Springer-Verlag Berlin Heidelberg 2016

\section{Erratum to: Arch Orthop Trauma Surg \\ DOI 10.1007/s00402-015-2357-9}

The author would like to correct the errors in the publication of the original article. The corrected details are given below for your reading.

In "Results" section, fourth and fifth sentence should read as:

Only 1 out of 78 fractures had a single additional lesion, a lesion of the triangular fibrocartilage complex (TFCC). This patient resulted with a Castaing score of 4, respectively ("good").

The online version of the original article can be found under doi:10.1007/s00402-015-2357-9.

Renata Gologan

renata.gologan@umm.de

1 Orthopädisch-Unfallchirurgisches Zentrum,

Universitätsmedizin Mannheim, Medizinische Fakultät

Mannheim der Ruprecht-Karls-Universität Heidelberg,

Theodor-Kutzer-Ufer 1-3, 68167 Mannheim, Germany

2 Alameda County Medical Center, Oakland, CA, USA 